place in the management of premature labour. Ritodrine has been studied more extensively than the other beta ${ }_{2}$-sympathomimetic agents, but one report found very little difference in side effects between ritodrine and fenoterol. ${ }^{17}$ Further studies will be required to see whether there are any subtle, but possibly important, differences between the different betasympathomimetic drugs. Furthermore, beta-mimetics are not harmless. They may cause acute pulmonary oedema in the mother when used in conjunction with corticosteroids to induce maturity of the fetal lung. ${ }^{18-20}$ They also induce tachycardia, palpitations, and hypotension and should not be used in patients with heart disease or hyperthyroidism. ${ }^{21}$

In an earlier leading article ${ }^{22}$ we described the use of drugs in the management of preterm labour as "usually unnecessary, frequently ineffective, and occasionally harmful." Little has changed since then. Nevertheless, prematurity remains a major cause of perinatal death and further controlled trials, probably multicentre ones, are required before the treatment of premature labour can be put on a rational basis.

${ }^{1}$ Walters WAW, Wood C. A trial of oral ritodrine for the prevention of premature labour. Brf Obstet Gynaecol 1977;84:26-30.

${ }^{2}$ Spellacy WN, Cruz AC, Birk SA, Buhi WC. Treatment of premature labor with ritodrine: a randomized controlled study. Obstet Gynecol $1979 ; 54: 220-3$.

3 Larsen JF, Hansen MK, Hesseldahl H, et al. Ritodrine in the treatment of preterm labour. A clinical trial to compare a standard treatment with three regimens involving the use of ritodrine. $\mathrm{Br} \mathcal{F}$ Obstet Gynaecol $1980 ; 87: 949-57$.

4 Heyting A. Ritodrine in the treatment of preterm labour. A clinical trial to compare a standard treatment with three regimens involving the use of ritodrine. Br $\mathcal{F}$ Obstet Gynaecol 1980;87:1056.

5 Wesselius-de Casparis A, Thiery M, Yo Le Sian A, et al. Results of double-blind multicentre study with ritodrine in premature labour. Br Med F 1971;iii:144-7.

- Fuchs F. Prevention of prematurity. Am $\mathcal{F}$ Obstet Gynecol 1976;126:80917.

${ }^{7}$ Lauersen NH, Merkatz IR, Tejani N, et al. Inhibition of premature labour. A multicenter comparison of ritodrine and ethanol. Am $\mathcal{F}$ Obstet Gynecol 1977;127:837-45.

8 Ingermarsson I. Effect of terbutaline on premature labor. A double-blind placebo-controlled study. Am F Obstet Gynecol 1976;125:520-4.

- Brown SM, Tejani NA. Tebutaline sulfate in the prevention of recurrence of premature labor. Obstet Gynecol $1981 ; 57: 22-5$.

${ }^{10}$ Csapo AI, Herezeg J. Arrest of premature labor by isoxsuprine. $A m \mathcal{F}$ Obstet Gynecol 1977;129:482-91.

11 Merkatz IR, Peter JB, Barden TP. Ritodrine hydrochloride. A betamimetic agent for use in preterm labour. II. Evidence of efficacy. Obstet Gynecol 1980;56:7-12.

12 Fifth Study Group of the Royal College of Obstetricians and Gynaecologists. Beta-adrenergic agonists. In : Anderson A, Beard R, Brudenell JM, Dunn PM, eds. Preterm labour. Proceedings of the Fifth Study Group of the Royal College of Obstetricians and Gynaecologists 1977. London: Royal College of Obstetricians and Gynaecologists, 1978: 134-220.

13 Creasy RK, Golbus MS, Laros RK Jr, Parer JT, Roberts JM. Oral ritodrine maintenance in the treatment of preterm labour. Am $\mathcal{F}$ Obstet Gynecol 1980;137:212-9.

14 Zuckerman $\mathbf{H}$, Reiss U, Rubinstein I. Inhibition of human premature labor by indomethacin. Obstet Gynecol $1974 ; 44: 787-92$.

15 Sharpe GL, Thalme B, Larsson KS. Studies on closure of the ductus arteriosus. XI. Ductal closure in utero by a prostaglandin synthetase inhibitor. Prostaglandins 1974 ;8:363-8.

16 Steer CM, Petrie RH. A comparison of magnesium sulfate and alcohol for the prevention of premature labor. Am $\mathcal{F}$ Obstet Gynecol 1977;129:1-4.

17 Richter R, Hinselmann MJ. The treatment of threatened premature labor by betamimetic drugs: a comparison of fenoterol and ritodrine. Obstet Gynecol 1979;53:81-7.

18 Elliott HR, Abdulla U, Hayes PJ. Pulmonary oedema associated with ritodrine infusion and betamethasone administration in premature labour. $\mathrm{Br} \mathrm{Med} \mathrm{F} \mathrm{1978;ii} \mathrm{:799-800.}$

19 Tinga DJ, Aarnoudse JG. Post-partum pulmonary oedema associated with preventive therapy for premature labour. Lancet $1979 ; \mathrm{i}: 1026$

20 Stubblefield PG. Pulmonary edema occurring after therapy with dexamethasone and terbutaline for premature labor: a case report. $A m \mathcal{F}$ Obstet Gynecol 1978;132:341-2.

21 Barden TP, Peter JB, Merkatz IR. Ritodrine hydrochloride: a betamimetic agent for use in preterm labor. I. Pharmacology, clinical history, administration, side effects, and safety. Obstet Gynecol 1980;56:1-6.

22 Anonymous. Drugs in threatened preterm labour. Br Med $\mathcal{f} 1979 ; \mathrm{i}: 71$.

\section{Treatment of acute mountain sickness}

For centuries it has been known that persons who climb to high altitude are likely to suffer from acute mountain sickness. The symptoms of the mild form include headache, nausea, anorexia, and weakness and are experienced by half of people ascending above 14000 feet. Nearly 5\% suffer from the severe form with cerebral or pulmonary oedema. ${ }^{1}$ It is seen in climbers, soldiers, and skiers but, most frequently, in trekkers, partly because of their large numbers, and partly because they usually live at sea level and do not leave sufficient time to acclimatise. In the Himalayas alone over 200000 men and women undertake high-altitude treks each year, and their numbers are rapidly increasing.

Doctors need, therefore, both to understand mountain sickness and to be able to treat it. Unfortunately the underlying cause of acute mountain sickness is not clear, though hypoxia, alkalosis, exercise, and alterations in the production of cerebrospinal fluid may all be relevant. ${ }^{2}$ Hypoxia has been thought unlikely to be the sole cause, but in a recent controlled study ${ }^{3}$ the symptoms of mountain sickness were shown to be highly correlated with arterial hypoxia. In the same individuals arterial hypoxia also correlated with proteinuria ${ }^{4}$ and cerebral performance tests. Since hypoxia can cause cerebral oedema ${ }^{5}$ and may cause pulmonary oedema, ${ }^{6}{ }^{7}$ most of the features of acute mountain sickness could be attributed solely to oxygen lack. Acute mountain sickness is less well correlated with alkalosis $^{3}$ and occurs in the absence of exercise. ${ }^{2}$ These aspects must be of secondary importance.

If hypoxia is the main cause of acute mountain sickness then increasing oxygen supply to the tissues should help. Breathing from oxygen apparatus may be beneficial ${ }^{7}$ but in terms of trekking to altitude it is impracticable. There has, therefore, been considerable interest in drug treatment. Acetazolamide has been shown in several studies 38 to reduce arterial hypoxia at altitude and now this has been linked with the degree of acute mountain sickness. ${ }^{3}$ The clinical features of the illness are subjective, but the pronounced reduction in altitude proteinuria of those taking acetazolamide indicates its beneficial effect on the body.

The drug probably acts by causing a metabolic acidosis leading to an increased hypoxic drive to ventilation and thereby increased tissue oxygenation. More potent analogues of acetazolamide may be preferable, and methylprogesterone might also be useful. ${ }^{9}$ The appropriate dosage of the drugs and their relation to hypoxia need to be assessed, particularly at night when profound oxygen desaturation occurs. ${ }^{10}$ Other drugs tried in acute mountain sickness include spironolactone and frusemide. These drugs have been aimed at reducing the fluid retention, but they have no effect on tissue oxygenation, and none has been of proved benefit. ${ }^{11}$

Use of acetazolamide as a prophylactic for acute mountain sickness should help to reduce much of the suffering of those who trek, climb, and live at high altitude and by increasing mental alertness might even decrease mountaineering accidents. It is, however, not a panacea. Acetazolamide does have occasional severe side effects and, as with oxygen treatment, is unlikely to be of much use in the established case. People will still suffer from acute mountain sickness if they ascend too fast.

${ }^{1}$ Hackett PH, Rennie D, Levine HD. The incidence, importance, and prophylaxis of acute mountain sickness. Lancet 1976;ii:1149-54,5. 
2 Forwand SA, Landowne M, Follansbee JN, Jansen IE. Effect of acetazolamide on acute mountain sickness. $N$ Engl $\mathcal{f}$ Med 1968;279:839-45.

${ }^{3}$ Birmingham Medical Research Expeditionary Society Mountain Sickness Study Group. Acetazolamide in the control of acute mountain sickness. Lancet $1981 ; \mathrm{i}: 180-3$.

${ }^{4}$ Bradwell AR, Delamere JP. The effect of acetazolamide on proteinuria at altitude. Clin $S c i$ (in press).

${ }^{5}$ Fishman RA. Brain edema. N Engl f Med 1975 ;293 :706-11.

${ }^{6}$ Reid L, Meyrick B. Hypoxia and pulmonary vascular endothelium. In: Metabolic activities of the lung. Ciba Foundation Symposium 78 (New series). Amsterdam: Excerpta Medica, 1980:37-60.

${ }^{7}$ Houston CS. High altitude illness. Disease with protean manifestations. f AMA 1976;236:2193-5.

${ }^{8}$ Cain SM, Dunn JE. Increase in arterial oxygen tension at altitude by carbonic anhydrase inhibition. 7 Appl Physiol $1965 ; 20: 882-4$

${ }^{9}$ Leitch AG. The hypoxic drive to breathing in man. Lancet 1981 ; :428-30.

10 Sutton JR, Houston CS, Mansell AL, et al. Effect of acetazolamide on hypoxemia during sleep at high altitude. $N$ Engl f Med 1979;301:132931 .

${ }^{11}$ Heath D, Williams DR. Man at high altitude: the pathophysiology of acclimatization and adaptation. Edinburgh: Churchill Livingstone, 1977:104-20.

\section{Artificial ventilation and the heart}

Intermittent alterations of stroke volume and asynchronism of output of the two ventricles are known to occur during both spontaneous breathing and artificial ventilation. ${ }^{1}$ The effect of intermittent positive-pressure ventilation (particularly when the inspiratory phase is prolonged) is to raise the mean intrathoracic pressure and to lower both the stroke volume and the cardiac output. ${ }^{23}$ This reduction of cardiac output has usually been attributed to reduced venous return, increased pulmonary vascular resistance or impedance, and reduced pulmonary blood volume. ${ }^{4}$ The finding that hypovolaemia increases the effect of artificial ventilation on the circulation has reinforced the view that the important factor is reduced filling of the right ventricle. ${ }^{5}$

Positive end-expiratory pressure ${ }^{6}$ is widely used to improve oxygenation in patients with acute lung damage. This technique of continuous positive-pressure ventilation raises the mean intrathoracic pressure substantially; and the cardiac output decreases as the pressure in the airways increases. ${ }^{7}$ During positive end-expiratory pressure ventilation a rise in the volume of the circulating blood raises the cardiac output, ${ }^{8}$ so that again reduced venous return has been thought to be the most important determinant of the effect of positive end-expiratory pressure on the circulation. On the other hand, the observation that dopamine is also effective ${ }^{9}$ suggests that myocardial depression may also be important in the circulatory depression induced by positive end-expiratory pressure. Furthermore, isolated heart muscle preparations are depressed by the addition of plasma from animals subjected to positive endexpiratory pressure, ${ }^{10}$ promoting the suggestion that substances with a negative inotropic effect may be released as the lungs are stretched. Stretching of the lungs may modify the metabolism of prostaglandins, ${ }^{11}$ one of which is thought to possess negative inotropic properties. ${ }^{12}$ This hypothesis of release of negative inotropic substance into the circulation could explain the observation that positive end-expiratory pressure may greatly reduce the cardiac output even though the chest wall has been removed ${ }^{13}{ }^{14}$-when the lungs are stretched to their maximum but venous return is unimpeded. The same hypothesis could also explain why when the chest is open and the pulmonary pressure is raised positive endexpiratory pressure reduces cardiac output more than constriction of the pulmonary artery. ${ }^{13}$

Yet another possibility is that the cardiac performance might be depressed by circulatory reflexes elicited by stretching the lungs: but the reduction of the cardiac output induced by positive end-expiratory pressure persists in vagotomised animals treated with beta-adrenoceptor antagonists ${ }^{15}$ whose circulatory reflexes have been substantially blunted if not abolished. Finally, the myocardial depression might be due to reduction of or abnormal distribution of coronary blood flow; but this possibility has been disproved by the persistence of the effects of positive end-expiratory pressure on cardiac output while coronary flow and its distribution remained normal. ${ }^{16}$

Some studies have found no evidence of myocardial depression $^{810}$ during positive end-expiratory pressure, possibly because of inconsistencies in the evaluation of intravascular pressures. While positive end-expiratory pressure increases intravascular pressures relative to atmospheric pressure it may decrease transmural pressure if intrapleural, intraoesophageal, or intrapericardial pressures are taken into account. In some studies lower cardiac output was associated with reduced transmural pressures, ${ }^{8}$ while in others it was associated with raised transmural pressures. ${ }^{13} 141617$ The latter condition has often been interpreted as evidence of cardiac depression, but an alternative explanation for lower stroke volume and higher transmural pressure is a decrease of diastolic ventricular compliance.

A factor receiving increasing attention is the part played by the pericardium. This structure has a low compliance and is an important determinant of the relations between the two ventricles. ${ }^{1819}$ When the pericardium is intact the right and left ventricular filling pressures are tightly correlated and changes in right ventricular afterload modify the preload of both the right and the left ventricle. Right ventricular loading modifies the configuration of the left ventricle and the relations between diastolic pressure and volume $\mathrm{e}^{20}$ by flattening the interventricular septum. ${ }^{2122}$ Positive end-expiratory pressure inevitably causes right ventricular loading, and indeed in patients with acute lung damage positive endexpiratory pressure increases the radius of curvature of the septum. ${ }^{23}$ Positive end-expiratory pressure also decreases the cross-sectional area of the left ventricle both at end-diastole and end-systole in a dose-dependent fashion. At high levels of positive end-expiratory pressure the radius of curvature of the septum may become further increased-and what has been interpreted as left ventricular failure may, in fact, because of the interdependence of the two ventricles, represent failure to fill and not failure to eject. ${ }^{24}$

One more factor that needs to be taken into account is alteration of carbon dioxide tension, since hypocapnia is known to reduce the cardiac output-and the full complexity of the relation of intermittent positive-pressure ventilation and the heart is now apparent. All these factors may assume greater or less importance according to the condition of the patient.

${ }^{1}$ Hoffman JIE, Guz A, Charlier AA, Wilcken DEL. Stroke volume in conscious dogs: effect of respiration, posture and vascular occlusion. f Appl Physiol 1965;20:865-77.

${ }^{2}$ Cournand A, Motley HL, Werkö L, Richards DW. Physiological studies of the effects of intermittent positive pressure breathing on cardiac output in man. Am $\mathcal{F}$ Physiol 1948;152:162-74.

${ }^{3}$ Werkö $\mathrm{L}$. The influence of positive pressure breathing on the circulation in man. Acta Med Scand 1947; suppl 193:1-125.

${ }^{4}$ Charlier AA. Beat to beat haemodynamic effects of lung inflation and normal respiration in anaesthetized and conscious dogs. Brussels: Presses Academiques Europeennes, 1968. 